\title{
DEK is highly expressed in breast cancer and is associated with malignant phenotype and progression
}

\author{
MAI-QING YANG ${ }^{1,2 *}$, LIN-LIN BAI $^{3 *}$, ZHAO WANG $^{1,4}$, LEI LEI $^{1}$, YI-WEN ZHENG ${ }^{1}$, \\ ZHI-HAN LI ${ }^{1}$, WEN-JING HUANG ${ }^{1}$, CHEN-CHEN LIU ${ }^{1}$ and HONG-TAO XU ${ }^{1}$ \\ ${ }^{1}$ Department of Pathology, The First Hospital and College of Basic Medical Sciences of China Medical University, \\ Shenyang, Liaoning 110001; ${ }^{2}$ Department of Pathology, Changyi People's Hospital, Changyi, Shandong 261300; \\ ${ }^{3}$ Department of Pathology, Shenyang 242 Hospital, Shenyang, Liaoning 110034; ${ }^{4}$ Department of Pathology, \\ General Hospital of Heilongjiang Land Reclamation Bureau, Harbin, Heilongjiang 150088, P.R. China
}

Received December 9, 2020; Accepted March 10, 2021

DOI: $10.3892 / \mathrm{ol} .2021 .12701$

\begin{abstract}
DEK proto-oncogene (DEK) has been demonstrated as an oncogene and is associated with the development of many types of tumor; however, the expression and role of DEK in breast cancer remain unknown. The present study aimed to determine the role of DEK in the progression of breast cancer. The expression of DEK in 110 breast cancer tissues and 50 adjacent normal breast tissues was examined using immunohistochemistry. Furthermore, DEK expression was upregulated by DEK transfection or downregulated by DEK shRNA interference in MCF7 cells. Proliferative and invasive abilities were examined in MCF7 cells using MTT assay, colony-formation assay and transwell invasion assays. The results demonstrated that DEK expression level was significantly increased in breast cancer tissues compared with normal breast tissues. Furthermore, high DEK expression was associated with high histological grade, lymph node metastasis, advanced Tumor-Node-Metastasis stage and high Ki-67 index; however, DEK expression was not associated with the expression level of estrogen receptor, progesterone receptor, and human epidermal growth factor receptor 2 . High DEK expression indicated poor prognosis in patients with breast cancer. DEK overexpression upregulated the protein
\end{abstract}

Correspondence to: Professor Hong-Tao Xu, Department of Pathology, The First Hospital and College of Basic Medical Sciences of China Medical University, 155 Nanjingbei Street, Heping, Shenyang, Liaoning 110001, P.R. China

E-mail: xuht@cmu.edu.cn

*Contributed equally

Abbreviations: ER, estrogen receptor; Gsk, glycogen synthase kinase; Her-2, human epidermal growth factor receptor 2; PR, progesterone receptor; TCGA, The Cancer Genome Atlas; TNM, tumor-node-metastasis; TNBC, triple negative breast cancer

Key words: DEK proto-oncogene, breast cancer, prognosis, progression expression of $\beta$-catenin and $\mathrm{Wnt}$ and increased the proliferative and invasive abilities of breast cancer cells. DEK downregulation had the opposite effect. Taken together, the results from the present study demonstrated that high expression of DEK was common in patients with breast cancer and was associated with progression of the disease and poor prognosis, and that DEK overexpression promoted the proliferative and invasive abilities of breast cancer cells.

\section{Introduction}

Breast cancer is the most common cancer in the world, and in the United States breast cancer alone accounted for $30 \%$ of all new cancer diagnoses in women in 2019 (1). The 5-year survival of patients with breast cancer has been improved due to recent advances in surgical therapy, radiotherapy, hormone therapy and immunotherapy. The death rate for patients with breast cancer dropped by $40 \%$ between 1989 and $2016(1,2)$. The main causes of mortality are attributed to distant metastasis and disease recurrence (3). Early diagnosis of breast cancer is crucial for effective treatment (4). Determining some novel biomarkers and targets remains therefore crucial to develop efficient therapies for breast cancer.

DEK proto-oncogene (DEK) is a highly conserved endogenous DNA-binding chromatin nuclear factor that encodes a 375 amino acid protein (5). DEK was initially described as part of the protein product of the DEK-CAN fusion oncogene generated by a $t(6 ; 9)$ translocation in a subset of patients with acute myelogenous leukemia $(6,7)$. DEK is one of only two known secreted nuclear chromatin factors. Its ability to bind nucleic acids leads to the regulation of numerous cellular processes, including the regulation of hematopoiesis, global heterochromatin integrity, DNA replication, gene transcription and DNA repair (5,8-12). DEK has therefore been associated with tumor formation and development. DEK has been reported to be overexpressed in numerous types of tumor, including lung cancer, gastric adenocarcinoma, cervical cancer, pancreatic cancer, hepatocellular carcinoma, ovarian cancer and oropharyngeal squamous cell carcinoma (13-22). In addition, high expression of DEK has been associated with low overall survival in patients with lung cancer (23). Silencing of 
DEK and inhibitor of nuclear factor kappa B can block the cell cycle in the $\mathrm{G}_{0} / \mathrm{G}_{1}$ phase, with a corresponding decrease in the $\mathrm{G}_{2} / \mathrm{M}$ phase, increased apoptosis and induced cell senescence in CaSki cervical cancer cells (24). These findings indicate that DEK might have an oncogenic role in tumorigenesis and neoplastic progression; however, the protein expression and role of DEK in breast cancer have not been extensively investigated.

In the present study, the association between DEK expression and the clinicopathological characteristics of patients with breast cancer was determined. In addition, the function of DEK in the proliferative and invasive abilities of MCF7 breast cancer cells was investigated to elucidate the significance of DEK in the progression of breast cancer.

\section{Materials and methods}

Patients and clinicopathological characteristics. A total of 110 patients with invasive ductal cancer were randomly selected and included in the present study. These patients underwent surgical resection at the First Affiliated Hospital of China Medical University (Shenyang, Liaoning, China) between January 2011 and December 2016. Tissues from 50 cases of breast cancer were matched with adjacent normal breast tissues ( $>2-\mathrm{cm}$ away from the tumor). All patients were women and none underwent chemotherapy or radiotherapy prior to surgical resection. All tissue specimens were fixed with $10 \%$ neutral formalin at room temperature after surgery for pathological examination and were diagnosed as invasive ductal cancers by pathological examination. The mean age of patients was 58 years (age range, 31-85 years). The clinicopathological characteristics of patients, including age, tumor differentiation, histological grade, lymph node metastasis, tumor-node-metastasis (TNM) stage, and expression of estrogen receptor (ER), progesterone receptor (PR), human epidermal growth factor receptor 2 (Her-2) and Ki-67, were retrospectively investigated. The TNM stage of patients with breast cancer was classified as stages I-II $(n=62)$ and stages III-IV $(n=48)$ according to the TNM staging system of the International Union Against Cancer (25). The research protocol was reviewed and approved by the local Institutional Review Board of the China Medical University.

Immunohistochemistry. For immunohistochemical analysis, all tumor specimens were fixed in $10 \%$ neutral formalin for $24 \mathrm{~h}$ at room temperature and embedded in paraffin blocks. Sections (4- $\mu \mathrm{m}$ thick) were cut and placed onto glass slides precoated with 2\% 3-aminopropyl triethoxysilane for $1 \mathrm{~h}$ at room temperature (Fuzhou Maixin Biotech Co., Ltd.). Immunostaining was performed using the streptavidin-peroxidase complex method. The sections were deparaffinized in xylene at room temperature, rehydrated in an $85-95 \%$ anhydrous alcohol gradient series and boiled in $0.01 \mathrm{M}$ citrate buffer ( $\mathrm{pH}$ 6.0) for $2 \mathrm{~min}$ in an autoclave. Endogenous peroxidase activity was blocked using $0.3 \%$ hydrogen peroxide at $37^{\circ} \mathrm{C}$ for $10 \mathrm{~min}$ and sections were subsequently incubated with $10 \%$ normal goat serum (Fuzhou Maixin Biotech Co., Ltd.) at $37^{\circ} \mathrm{C}$ to reduce nonspecific binding. The sections were incubated with the rabbit polyclonal antibody against DEK (cat. no. 16448-1-AP; 1:150; ProteinTech Group, Inc.) or the ready-to-use primary antibodies against ER (cat. no. MAB-0062), PR (cat. no. MAB-0675), Her-2 (cat. no. MAB-0198) and Ki-67 (cat. no. MAB-0672) (ready to use; all Fuzhou Maixin Biotech Co., Ltd.) at $4^{\circ} \mathrm{C}$ overnight. Section stained with PBS only was considered as a negative control. After washing with PBS, the sections were incubated for $30 \mathrm{~min}$ at $37^{\circ} \mathrm{C}$ with secondary biotinylated goat anti-rabbit serum $\mathrm{IgG}$ antibody (cat. no. SPKIT-C2) and horseradish peroxidase-conjugated streptavidin-biotin (cat. no. SPKIT-A2) (ready to use; all Fuzhou Maixin Biotech Co., Ltd.). The staining was visualized using 3,3-diaminobenzidine (Fuzhou Maixin Biotech Co., Ltd.). Sections were then stained with hematoxylin for $10 \mathrm{~min}$ at $37^{\circ} \mathrm{C}$ and observed under $\mathrm{x} 400$ magnification using a light microscope (Olympus Corporation).

The evaluation of immunostaining was performed semi-quantitatively. Nuclear staining of the tumor cells was considered to be DEK positive. In total, 10 high-power representative fields were selected per slide, and the staining intensity and positive rate of tumor cells were scored. The intensity of the staining was scored as follows: 0, negative; 1 , weak; 2 , intermediate; and 3 , strong. The positive rate for each case was obtained by calculating the percentage of positively stained tumor cells on each slide and was scored as follows: 0 , negative; $1,1-25 \% ; 2,26-50 \% ; 3,51-75 \%$; and $4,>75 \%$. The scores for each tumor sample were multiplied to obtain a final score of 0 to 12 . A final score $\geq 6$ was defined as high DEK expression whereas a score $<6$ was defined as low DEK expression $(23,26)$.

The Cancer Genome Atlas (TCGA) data collection and analysis. The expression data of DEK in breast cancers molecular subtypes were obtained using the online database UALCAN (http://ualcan.path.uab.edu) (TCGA dataset of breast invasive carcinoma, $n=719)(27)$. Correlation analysis between DEK expression and Ki-67 and PCNA expression in breast cancers was retrieved from cBioPortal database (http://www.cbioportal.org/) [mRNA expression (microarray), $n=1,904](28,29)$. Survival curve for patients with breast cancer with high or low DEK expression $(n=4,929)$ was obtained from Kaplan-Meier plotter (http://kmplot.com/analysis/) (30).

Cell lines and transfection. The human breast cancer cell line MCF7 (luminal A subtype) was purchased from The Cell Bank of Type Culture Collection of The Chinese Academy of Sciences. Cells were cultured in DMEM (Invitrogen, Thermo Fisher Scientific, Inc.), supplemented with 10\% FBS (cat. no. FB15015; Clark Bioscience) and placed at $37^{\circ} \mathrm{C}$ in a humidified incubator containing $5 \% \mathrm{CO}_{2}$.

For transfection, MCF7 cells were seeded into 6-well plates for $24 \mathrm{~h}$ at $37^{\circ} \mathrm{C}$ and cultured to $70-80 \%$ confluence before transfection. The plasmids containing the DEK gene (pCMV6-DEK) or DEK short hairpin RNA (shRNA) sequences (pCMV6-shDEK) were synthesized by GENECHEM (Shanghai GeneChem Co., Ltd.). The corresponding empty vector pCMV6 or plasmid containing scrambled shRNA sequences served as negative controls. The plasmids $(2.5 \mu \mathrm{g})$ were transfected into cells using Lipofectamine ${ }^{\mathrm{TM}} 3000$ (Invitrogen; Thermo Fisher Scientific, Inc.) according to manufacturers' instructions at $37^{\circ} \mathrm{C}$. Subsequent experiments were performed $24 \mathrm{~h}$ after transfection. 
Western blotting. Cells were lysed using RIPA lysis buffer at $4^{\circ} \mathrm{C}$ (Pierce; Thermo Fisher Scientific, Inc.) and proteins were quantified using the Bradford method (31). Proteins $(60 \mu \mathrm{g})$ were separated by $10 \%$ SDS-PAGE and transferred onto PVDF membranes. Membranes were blocked in 5\% non-fat milk for $1 \mathrm{~h}$ at room temperature. The membranes were incubated with primary antibodies against DEK (cat. no. 16448-1-AP; 1:1,000; ProteinTech Group, Inc.), glycogen synthase kinase-3 $\beta$ (Gsk-3 $\beta$; cat. no. 5676; 1:1,000; Cell Signaling Technology, Inc.), cyclin D1 (cat. no. SC-8396; 1:100; Santa Cruz Biotechnology, Inc.), $\beta$-catenin (cat. no. 17565-1-AP), active $\beta$-catenin (cat. no. 51067-2-AP), c-Myc (cat. no. 67447-1-Ig) and GAPDH (cat. no. 60004-1-Ig) (all 1:1,000; ProteinTech Group, Inc.) overnight at $4^{\circ} \mathrm{C}$. Membranes were washed with tris-buffered saline containing $0.1 \%$ Tween-20 and were incubated with IgG antibody (cat. no. SA00001-1/2; 1:2,000; ProteinTech Group, Inc.) at $37^{\circ} \mathrm{C}$ for $2 \mathrm{~h}$. Bands were detected using enhanced chemiluminescence substrate (Pierce; Thermo Fisher Scientific, Inc.) and detected using a bioimaging system (DNR Bio-Imaging System, Ltd.). All the western blotting bands were probed from the same membrane. After each probing, the membranes were stripped using a stripping buffer (Beyotime Institute of Biotechnology) according to the manufacturers' protocol and re-probed for other proteins. Relative expression levels were normalized to endogenous control GAPDH, which were analyzed with ImageJ software (version 1.47; National Institutes of Health).

Colony formation assay. Cells were seeded in $6 \mathrm{~cm}$ cell culture dishes (1,000 cells per dish) $24 \mathrm{~h}$ after transfection and were cultured for 10 days. The medium was changed every 3 days. Cells were then washed with PBS and stained with hematoxylin for $10 \mathrm{~min}$ at room temperature. The number of colonies with $>50$ cells were counted using a bioimaging system (version 5.2.1; DNR Bio-Imaging Systems, Ltd.).

Cell proliferation assay. Cell proliferation was detected using Cell Counting Kit-8 (CCK-8; Dojindo Molecular Technologies, Inc.). Briefly, $24 \mathrm{~h}$ after transfection, cells were seeded into 96 -well plates $(3,000$ cells per well) in $100 \mathrm{ul}$ medium containing $10 \%$ FBS. CCK-8 reagent was added to each well $(1: 10, \mathrm{v} / \mathrm{v})$ and incubated for $2 \mathrm{~h}$ at $37^{\circ} \mathrm{C}$. Cell proliferation was assessed at days 1, 2, 3, 4 and 5. The absorbance was read at $450 \mathrm{~nm}$ using a microplate reader.

Cell migration and invasion assays. Cell migratory and invasive abilities were assessed using 24-well transwell chambers containing inserts of $8 \mu \mathrm{m}$ pore size (Costar; Corning, Inc.). For the invasion assay only, the upper side of the inserts were coated with Matrigel for at least $2 \mathrm{~h}$ at $37^{\circ} \mathrm{C}$. (1:8; BD Biosciences). MCF7 cells were seeded $\left(1.5 \times 10^{5}\right.$ cells/well $)$ in the upper chambers in $100 \mu \mathrm{l}$ medium supplemented with $2 \%$ FBS. To attract cells, the lower chambers were filled with $600 \mu \mathrm{l}$ medium containing $20 \%$ FBS. After $20 \mathrm{~h}$, cells that had migrated to the lower chambers were fixed with $4 \%$ paraformaldehyde and stained with hematoxylin for $10 \mathrm{~min}$ at $37^{\circ} \mathrm{C}$. The non-invading cells on the upper surface were cleared using a cotton swab. A total of 10 randomly selected high-power fields were observed under light microscopy (magnification, $\mathrm{x} 200$ ), and the numbers of migrated or invaded cells were counted (Motic Image Plus 2.0; Motic (Xiamen) Medical Diagnostic Systems Co. Ltd.) All experiments described were performed independently and in triplicate.

Statistical analysis. Statistical analysis was performed using SPSS version 17.0 (IBM Corp.). Associations between DEK expression and the clinicopathological characteristics of patients were analyzed using $\chi^{2}$ test and Student's t-test. Comparisons among two experimental groups were performed using two-tailed Student's t-test. The P-value threshold was adjusted using Bonferroni correction when comparing more than two groups using Student's t-test. $\mathrm{P}<0.05$ was considered to indicate a statistically significant difference.

\section{Results}

DEK protein expression is higher in breast cancer tissues compared with normal breast tissues. Immunohistochemistry was performed for 110 cases of breast cancer and 50 cases of adjacent normal breast tissues. The results demonstrated that DEK protein was mainly expressed in the nuclei of cancer cells. Furthermore, high DEK expression was observed in $62.7 \%$ (69/110) of breast cancer tissues, which was significantly higher than that in normal breast tissues $(12.0 \% ; \mathrm{P}=0.002$; Table I and Fig. 1A-C).

High DEK expression is associated with certain clinicopathological characteristics and poor prognosis of patients. The expression of DEK was associated with histological grade $(\mathrm{P}=0.01)$, lymph node metastasis $(\mathrm{P}=0.003)$, TNM stage $(\mathrm{P}=0.030)$ and $\mathrm{Ki}-67$ expression $(\mathrm{P}=0.028)$; however, DEK expression was not associated with ER expression ( $\mathrm{P}=0.070)$, $\mathrm{PR}$ expression $(\mathrm{P}=0.510)$, Her-2 expression $(\mathrm{P}=0.420)$ or patient age $(\mathrm{P}=0.290$; Table I and Fig. 1$)$. Furthermore, according to the cBioPortal database, it was also found that DEK expression was positively correlated with the expression of $\mathrm{Ki}-67(\mathrm{P}<0.001 ; \mathrm{n}=1,904)$ or proliferating cell nuclear antigen (PCNA; $\mathrm{P}<0.001 ; \mathrm{n}=1,904)$ (Fig. 2A and B), which are both indexes of proliferation (32).

In addition, according to Kaplan-Meier analysis using the online database KM-plotter, patients with high expression of DEK presented a significant shorter overall survival compared with patients with low DEK expression $(\mathrm{P}<0.01$; median survival, 163.46 months for the high expression cohort vs. 216.66 months for the low expression cohort; Fig. 2C). As seen in the UALCAN database, the expression of DEK was significantly higher in triple negative breast cancer (TNBC) compared with luminal breast cancer $(\mathrm{P}<0.001)$ and Her-2 positive breast cancer $(\mathrm{P}<0.001)$. However, the expression level of DEK was not significant different between luminal and Her2 positive subtypes of breast cancer $(\mathrm{P}=0.123$; Fig. 2D).

$D E K$ regulates the expression of $\beta$-catenin and target genes of Wht signaling pathway. Enhanced DEK expression by DEK gene transfection in MCF7 cells (MCF7-DEK) increased the expression of active- $\beta$-catenin and inhibited the expression of Gsk-3 $\beta(\mathrm{P}<0.05)$. The expression of cyclin D1 and c-Myc, which are target genes of the Wnt signaling pathway, was also significantly increased in MCF7-DEK cells $(\mathrm{P}<0.05)$. 
Table I. Association between DEK expression and the clinicopathological characteristics of patients with breast cancer.

\begin{tabular}{|c|c|c|c|c|}
\hline \multirow[b]{2}{*}{ Variable } & \multirow[b]{2}{*}{ Cases } & \multicolumn{2}{|c|}{ DEK } & \multirow[b]{2}{*}{ P-value } \\
\hline & & High expression & Low expression & \\
\hline Tissue & & & & 0.002 \\
\hline Normal breast tissue & 50 & 6 & 44 & \\
\hline Breast cancer & 110 & 69 & 41 & \\
\hline Histological grade & & & & 0.010 \\
\hline I & 16 & 5 & 11 & \\
\hline II-III & 94 & 64 & 30 & \\
\hline TNM stage & & & & 0.030 \\
\hline I-II & 62 & 33 & 29 & \\
\hline III-IV & 48 & 36 & 12 & \\
\hline Lymph node metastasis & & & & 0.003 \\
\hline Negative & 68 & 35 & 33 & \\
\hline Positive & 42 & 34 & 8 & \\
\hline Ki-67 index & & & & 0.028 \\
\hline High & 31 & 25 & 6 & \\
\hline Low & 79 & 44 & 35 & \\
\hline ER expression & & & & 0.070 \\
\hline Positive & 70 & 39 & 31 & \\
\hline Negative & 40 & 30 & 10 & \\
\hline PR expression & & & & 0.510 \\
\hline Positive & 64 & 38 & 26 & \\
\hline Negative & 46 & 31 & 15 & \\
\hline HER-2 expression & & & & 0.420 \\
\hline Positive & 48 & 27 & 20 & \\
\hline Negative & 63 & 42 & 21 & \\
\hline Age, years & & & & 0.290 \\
\hline$<51$ & 78 & 46 & 33 & \\
\hline$\geq 51$ & 32 & 23 & 8 & \\
\hline
\end{tabular}

TNM, Tumor-Node-Metastasis; ER, estrogen receptor; PR, progesterone receptor; Her-2, human epidermal growth factor receptor 2.
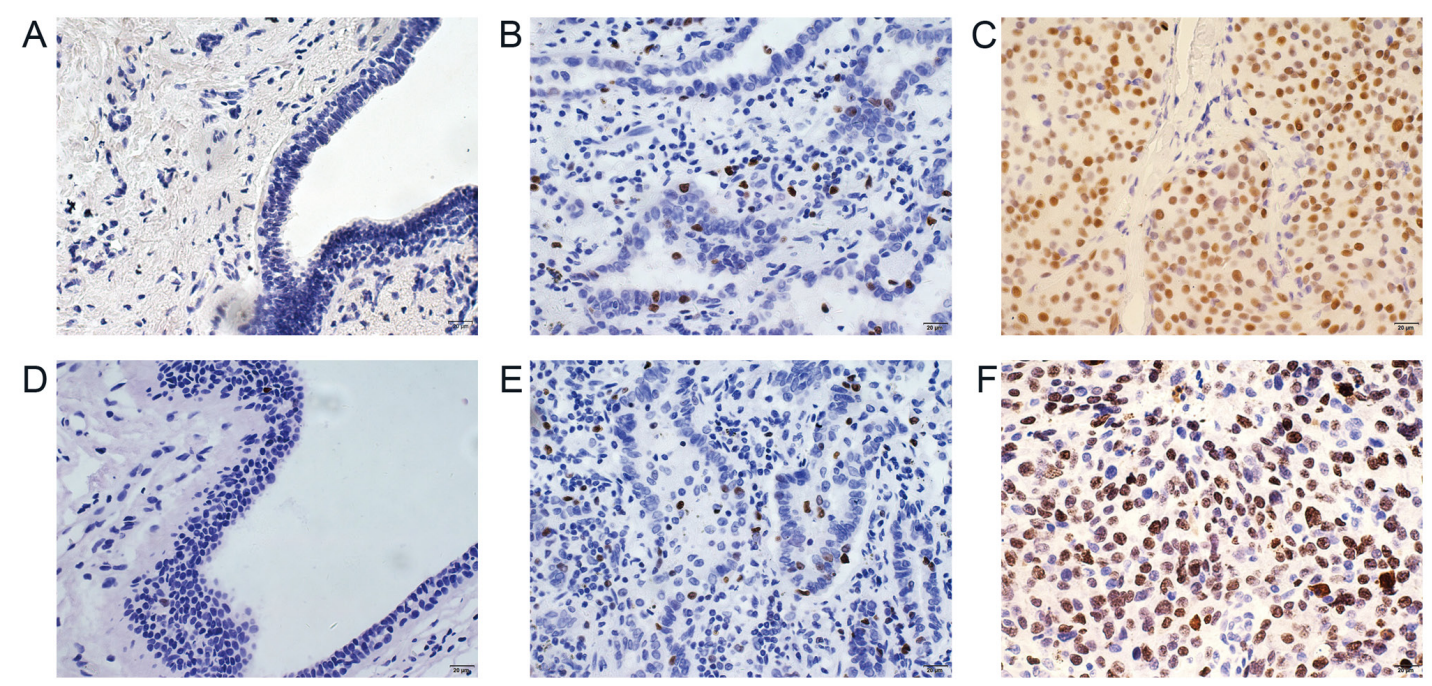

Figure 1. Expression of DEK and Ki-67 in breast cancers and normal breast tissues. (A) Expression of DEK in normal breast tissue. (B) Low expression of DEK in breast cancer, histological grade I. (C) High expression of DEK in breast cancer, histological grade III. (D) Expression of Ki-67 in normal breast tissues. (E) Low expression of Ki-67 in grade I breast cancer. (F) High expression of Ki-67 in grade III breast cancer. Magnification, x400. DEK, DEK proto-oncogene. 
A

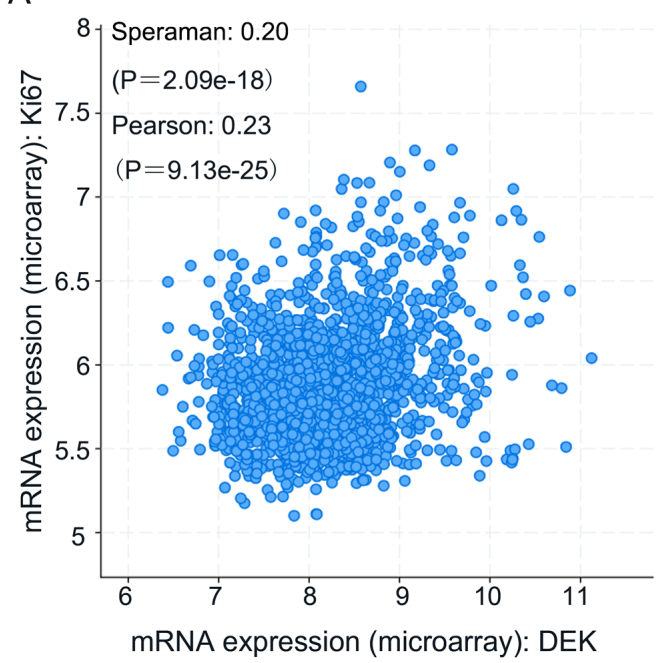

C

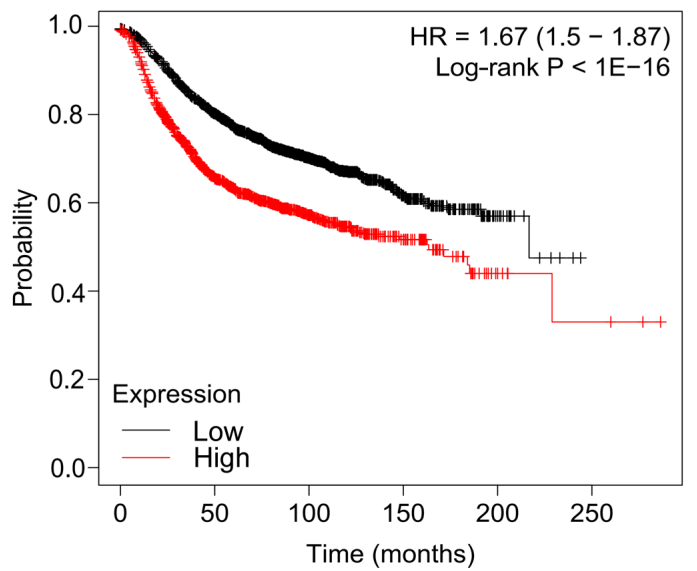

B

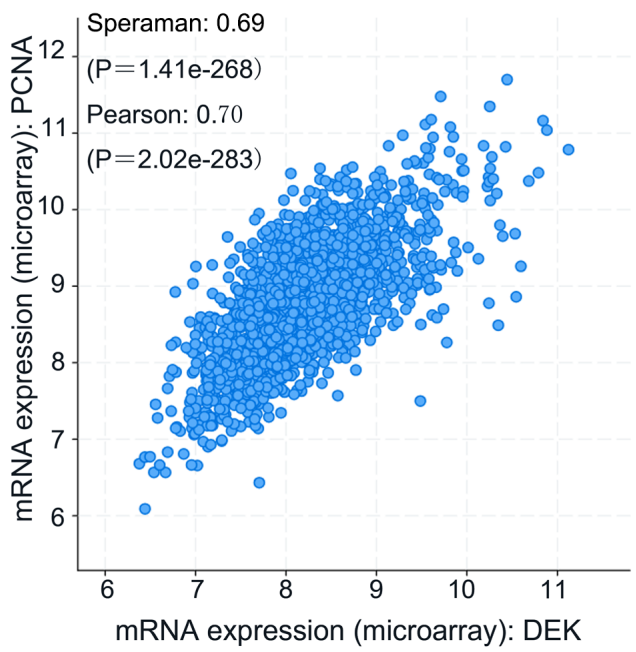

D

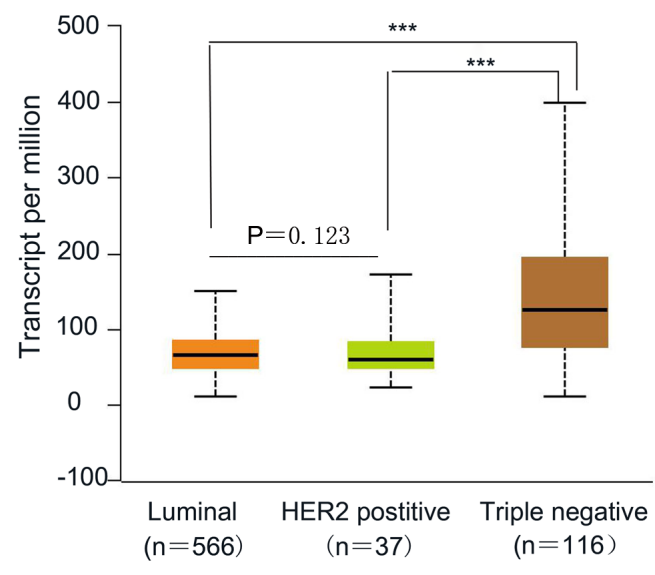

Figure 2. Correlation between DEK expression and some indexes of proliferation, prognosis and molecular subtypes of breast cancers. (A and B) Correlation analysis between DEK expression and Ki-67 and PCNA expression, which was retrieved from cBioPortal (http://www.cbioportal.org/). (C) Survival curve for patients with breast cancer with high or low DEK expression using KM-plotter (http://kmplot.com/analysis/). (D) Expression level of DEK in molecular subtypes of breast cancers from the UALCAN database (http://ualcan.path.uab.edu/). ${ }^{* * *} \mathrm{P}<0.001$. DEK, DEK proto-oncogene; PCNA, proliferating cell nuclear antigen; HR, hazard ratio.

However, the level of total $\beta$-catenin was not markedly changed following DEK overexpression ( $\mathrm{P}>0.05$; Fig. 3A and $\mathrm{B}$ ). Conversely, following DEK knockdown by shRNA interference (MCF7-ShDEK), the expression of active- $\beta$-catenin, cyclin D1 and c-Myc was significantly downregulated, whereas the expression of Gsk-3 $\beta$ was significantly increased in MCF7 cells $(\mathrm{P}<0.05)$. The level of total $\beta$-catenin was not changed following DEK knockdown ( $\mathrm{P}>0.05$; Fig. 3C and D).

DEK overexpression promotes the proliferation, colony formation and migratory and invasive abilities of breast cancer cells. Overexpression of DEK enhanced the proliferation rate $(\mathrm{P}<0.05$ for days 1 and $2 ; \mathrm{P}<0.01$ for days 3 and 4$)$ and the colony formation $(\mathrm{P}<0.05)$ of $\mathrm{MCF} 7$ cells compared with control cells. Conversely, following DEK knockdown, the proliferation rate $(\mathrm{P}<0.01$ for days 3, 4 and 5) and colony formation $(\mathrm{P}<0.05)$ of $\mathrm{MCF} 7$ cells were significantly inhibited compared with control cells (Fig. 4A and B).

Furthermore, DEK overexpression promoted the migratory and invasive abilities of MCF7 cells compared with control cells $(\mathrm{P}<0.01)$. Conversely, DEK downregulation inhibited the migratory and invasive abilities of MCF7 cells $(\mathrm{P}<0.01$; Fig. 5A and B).

\section{Discussion}

In order to accurately diagnose and treat cancers, researchers are working to determine novel effective markers to improve the clinical evaluation of outcomes and to develop targeted therapy. DEK has been reported to be overexpressed in numerous types of human cancer, including lung cancer, pancreatic cancer, gastric adenocarcinoma, ovarian cancer, cervical cancer, hepatocellular cancer and TNBC (13,15-19,21,33). DEK plays an active role in tumor initiation and maintenance. The expression of DEK has been associated with the clinicopathological characteristics of patients with hepatocellular cancers and pancreatic adenocarcinomas and described as an indicator of poor prognosis $(11,16)$, suggesting that DEK may be considered as a potential prognostic biomarker in various types of cancer. 

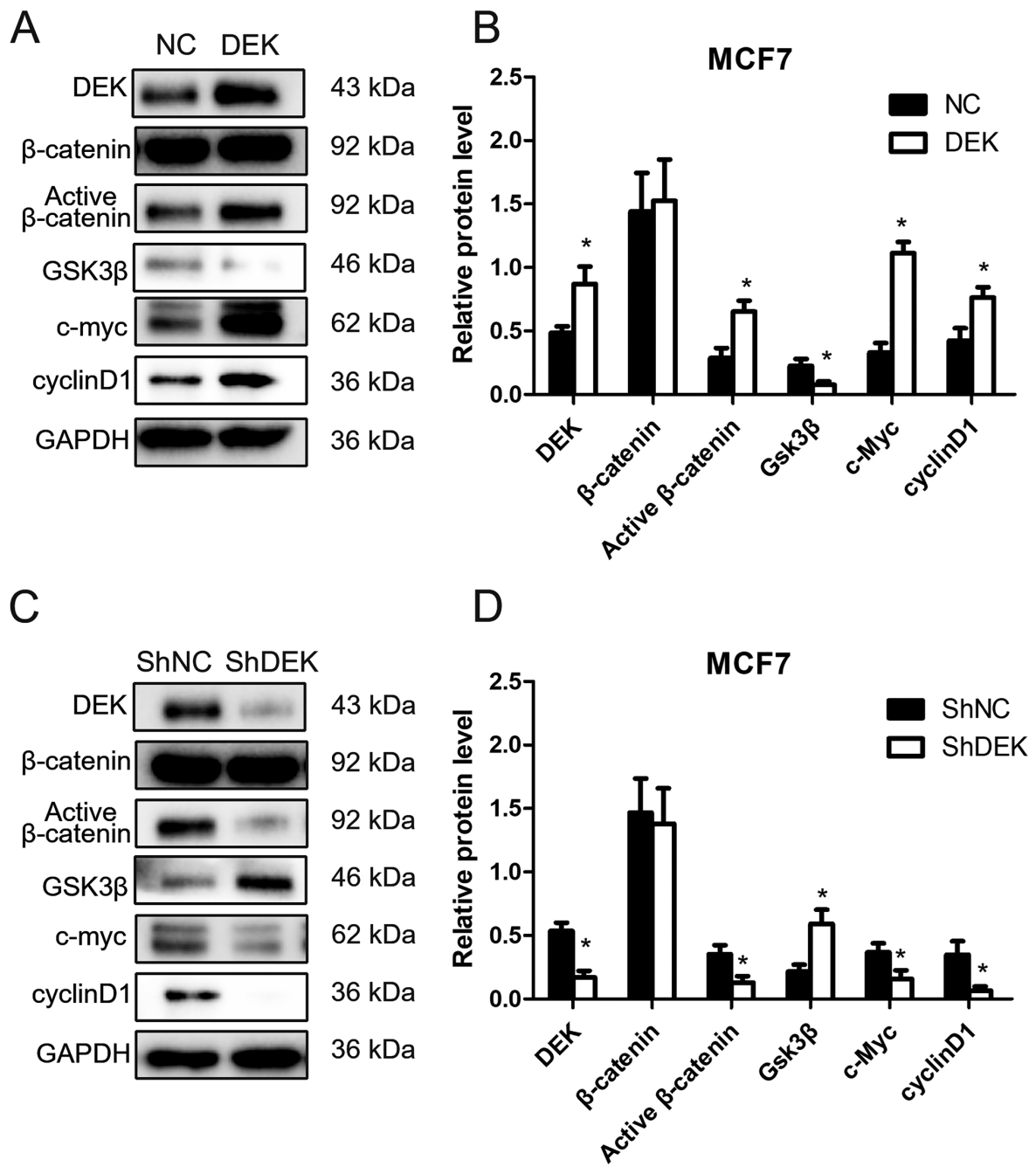

Figure 3. Expression of $\beta$-catenin and Wnt target proteins following overexpression and knockdown of DEK in breast cancer cells. (A and C) Representative western blotting bands and (B and D) quantification of protein expression in MCF7 cells. GAPDH served as an internal control. "P<0.05 DEK vs. NC or shDEK

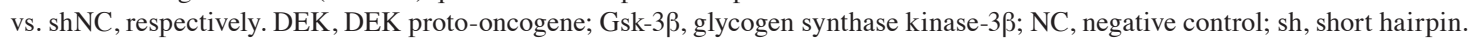

Although DEK overexpression has been reported in breast cancer (34-36), the expression pattern of DEK and its association with the clinicopathological characteristics of patients remain unclear. The present study demonstrated that DEK protein was present in cancer cell nucleus and that its expression was higher in breast cancer tissues compared with normal breast tissues. Furthermore, high DEK expression was associated with a high grade, advanced TNM stage and high index of proliferation, which is characterized by a high expression of Ki67 or PCNA, in patients with breast cancer. In addition, high expression of DEK could predict a poor prognosis in patients with breast cancer, suggesting that DEK may be considered as a potentially valuable prognostic marker in breast cancer. As seen in UALCAN database, DEK expression level was significantly higher in TNBC compared with luminal and Her-2 positive breast cancers; however, similar results were not observed in the population from the present study; which may be due to the limited sample size and the different types of detection methods. The present study only examined the protein expression of DEK using immunohistochemistry in paraffin embedded samples. The mRNA expression of DEK was not detected in the present study and should be investigated in the future using fresh breast cancer tissues.

DEK can regulate the proliferation, migration, invasion and apoptosis of cancer cells and be subjected to a variety of tumor-associated modifications $(37,38)$. It has been reported that DEK knockdown can inhibit the proliferation of ovarian, lung and cervical cancers $(15,23,39)$. The present study demonstrated that DEK overexpression promoted the proliferation, colony formation and invasive and migratory abilities of MCF7 cells, which was consistent with the results in vivo.

DEK is involved in cancer progression through the regulation of numerous signaling pathways. For example, DEK expression is regulated by the transcription factors Nuclear Factor-Y and Yin Yang-1 (40) and can be induced by high-risk human papillomavirus E7 to overcome cellular senescence (41). In addition, DEK is a regulator of the $G_{1}$ to $S$ transition and a potential target gene of the p16-pRB-E2F pathway (42). DEK regulates apoptosis in glioblastomas partly through modulating p53 by inhibiting its transcription activity and protein stability (38). Furthermore, blocking the PI3K/AKT/mammalian target of rapamycin pathway using specific inhibitors can 
A
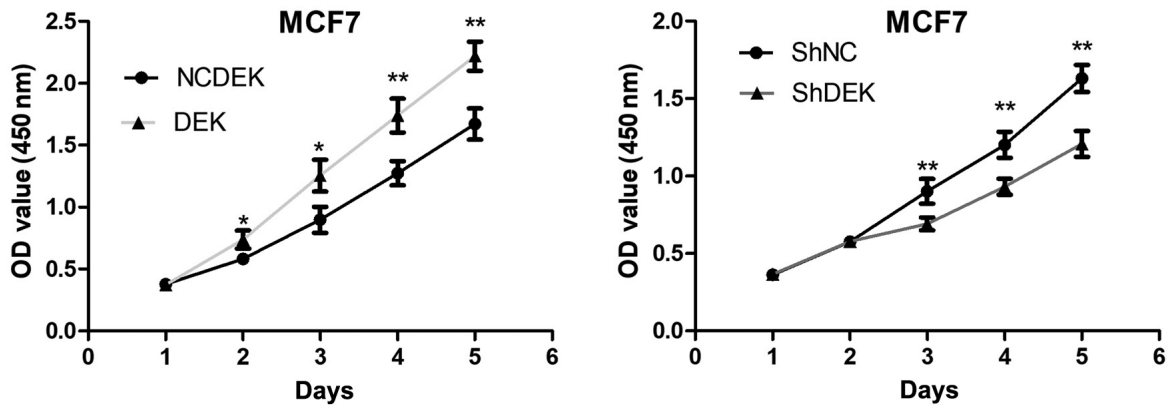

B
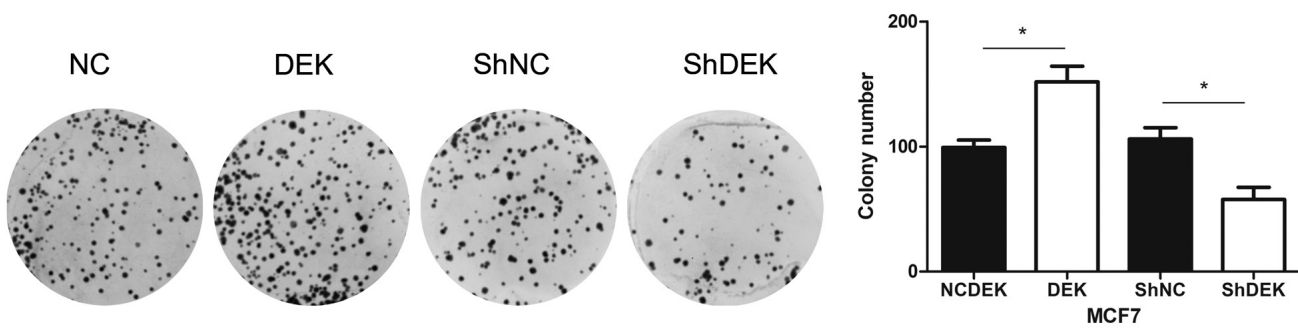

Figure 4. Effect of DEK on the proliferation and colony formation of breast cancer cells. (A) Cell Counting Kit-8 assay and (B) colony formation assay (magnification, $\mathrm{x} 200$ ) were performed following DEK overexpression or knockdown in MCF7 cells. ${ }^{*} \mathrm{P}<0.05$ and ${ }^{* *} \mathrm{P}<0.01$, DEK vs. NC or shDEK vs. shNC. DEK, DEK proto-oncogene; NC, negative control; sh, short hairpin.

A
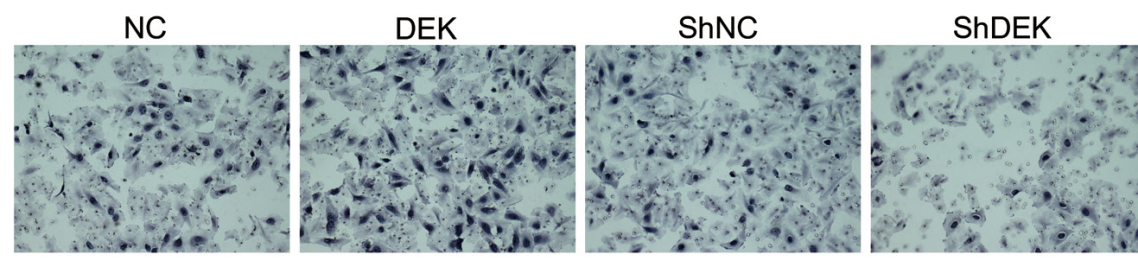

B
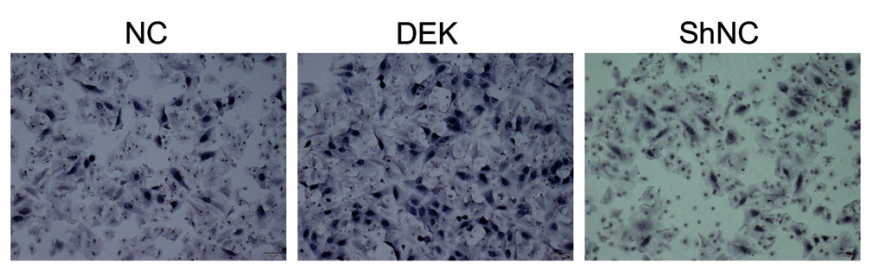

ShDEK

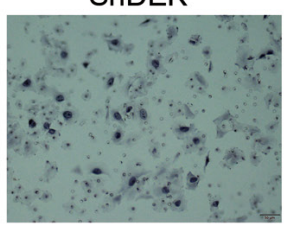

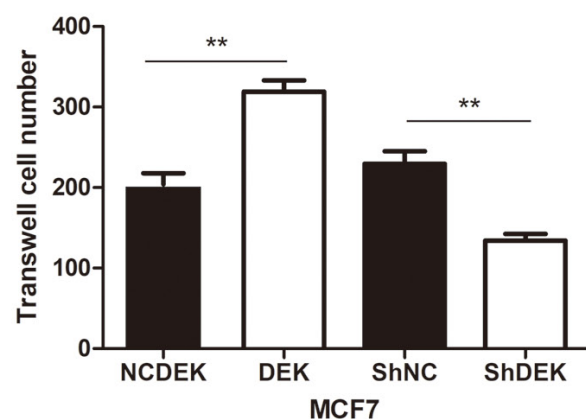

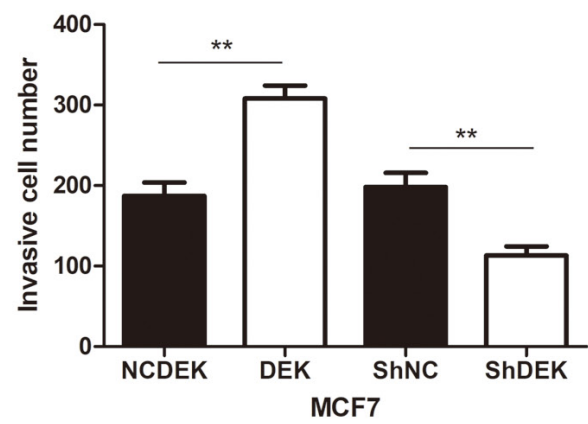

Figure 5. Effects of DEK on invasive and migratory abilities of breast cancer cells. (A) Transwell assays were performed to assess cell migratory and (B) following DEK overexpression or knockdown in MCF7 cells. Magnification, x200. ${ }^{* *} \mathrm{P}<0.01$, DEK vs. NC or shDEK vs. shNC. DEK. DEK, DEK proto-oncogene; $\mathrm{NC}$, negative control; sh, short hairpin.

significantly attenuate DEK-enhanced migration and angiogenesis in TNBCs (33). In cervical cancer, DEK promotes Hela cell metastasis via upregulation of the Wnt pathway and matrix metalloproteinase-9 expression (39). The results from the present study demonstrated that DEK could upregulate the expression of active $\beta$-catenin and Wnt target genes, such as cyclin D1 and c-Myc. DEK may therefore promote the proliferation and invasive ability of breast cancer by activating the Wnt signaling pathway. Taken together, these findings suggested that DEK may act as an oncogene and promote breast cancer development; however, the underlying oncogenic mechanism of DEK in breast cancer requires further investigation.

In conclusion, the results from the present demonstrated that high expression of DEK was common in breast cancer tissues. In addition, DEK overexpression promoted the proliferation and invasive ability of breast cancer cells in vitro, and 
was associated with high grade, advanced TNM stage and poor prognosis in patients with breast cancer.

\section{Acknowledgements}

Not applicable.

\section{Funding}

This study was supported by the Youth Scientific Research Foundation of Shenyang Medical College (grant no. 20182048) and the Natural Science Foundation of Liaoning Province (grant no. 2020-MS-179).

\section{Availability of data and materials}

The datasets used during the current study are available from the corresponding author on reasonable request.

\section{Authors' contributions}

HTX designed the study. MQY and HTX participated in drafting the manuscript. MQY, LLB, ZW, LL, YWZ, ZHL, WJH and CCL performed the experiments. MQY and HTX confirm the authenticity of all the raw data. All authors have read and approved the final manuscript.

\section{Ethics approval and consent to participate}

The research protocol was reviewed and approved by the local institutional review board at the China Medical University. Written informed consent was obtained from all patients.

\section{Patient consent for publication}

Not applicable.

\section{Competing interests}

The authors declare that they have no competing interests.

\section{References}

1. Siegel RL, Miller KD and Jemal A: Cancer statistics, 2019. CA Cancer J Clin 69: 7-34, 2019.

2. Bray F, Ferlay J, Soerjomataram I, Siegel RL, Torre LA and Jemal A: Global cancer statistics 2018: GLOBOCAN estimates of incidence and mortality worldwide for 36 cancers in 185 countries. CA Cancer J Clin 68: 394-424, 2018.

3. Gonzalez-Angulo AM, Morales-Vasquez F and Hortobagyi GN: Overview of resistance to systemic therapy in patients with breast cancer. Adv Exp Med Biol 608: 1-22, 2007.

4. Redig AJ and McAllister SS: Breast cancer as a systemic disease: A view of metastasis. J Intern Med 274: 113-126, 2013.

5. Kappes F, Scholten I, Richter N, Gruss C and Waldmann T: Functional domains of the ubiquitous chromatin protein DEK Mol Cell Biol 24: 6000-6010, 2004.

6. Fu GK, Grosveld G and Markovitz DM: DEK, an autoantigen involved in a chromosomal translocation in acute myelogenous leukemia, binds to the HIV-2 enhancer. Proc Natl Acad Sci USA 94: 1811-1815, 1997 .

7. Boer J, Mahmoud H, Raimondi S, Grosveld G and Krance R: Loss of the DEK-CAN fusion transcript in a child with $\mathrm{t}(6 ; 9)$ acute myeloid leukemia following chemotherapy and allogeneic bone marrow transplantation. Leukemia 11: 299-300, 1997.
8. McGarvey T, Rosonina E, McCracken S, Li Q, Arnaout R, Mientjes E, Nickerson JA, Awrey D, Greenblatt J, Grosveld G and Blencowe BJ: The acute myeloid leukemia-associated protein, DEK, forms a splicing-dependent interaction with exon-product complexes. J Cell Biol 150: 309-320, 2000.

9. Kappes F, Burger K, Baack M, Fackelmayer FO and Gruss C: Subcellular localization of the human proto-oncogene protein DEK. J Biol Chem 276: 26317-26323, 2001.

10. Waldmann T, Eckerich C, Baack M and Gruss C: The ubiquitous chromatin protein DEK alters the structure of DNA by introducing positive supercoils. J Biol Chem 277: 24988-24994, 2002.

11. Lee SY, Jung W, Lee J, Kim A, Kim HK and Kim BH: High expression of DEK is associated with poor prognosis in hepatocellular carcinoma. Histol Histopathol 34: 1279-1288, 2019.

12. Capitano ML, Mor-Vaknin N, Saha AK, Cooper S, Legendre M, Guo H, Contreras-Galindo R, Kappes F, Sartor MA, Lee CT, et al: Secreted nuclear protein DEK regulates hematopoiesis through CXCR2 signaling. J Clin Invest 129: 2555-2570, 2019.

13. Smith EA, Kumar B, Komurov K, Smith SM, Brown NV, Zhao S, Kumar P, Teknos TN and Wells SI: DEK associates with tumor stage and outcome in HPV16 positive oropharyngeal squamous cell carcinoma. Oncotarget 8: 23414-23426, 2017.

14. Riveiro-Falkenbach E, Ruano Y, Garcia-Martin RM, Lora D, Cifdaloz M, Acquadro F, Ballestín C, Ortiz-Romero PL, Soengas MS and Rodríguez-Peralto JL: DEK oncogene is overexpressed during melanoma progression. Pigment Cell Melanoma Res 30: 194-202, 2017.

15. Hacker KE, Bolland DE, Tan L, Saha AK, Niknafs YS, Markovitz DM and McLean K: The DEK oncoprotein functions in ovarian cancer growth and survival. Neoplasia 20: 1209-1218, 2018.

16. Zhao T, Qiu B, Zhou S, Ding G, Cao L and Wu Z: Expression of DEK in pancreatic cancer and its correlation with clinicopathological features and prognosis. J Cancer 10: 911-917, 2019.

17. Serrano-Lopez J, Nattamai K, Pease NA, Shephard MS, Wellendorf AM, Sertorio M, Smith EA, Geiger H, Wells SI, Cancelas JA and Privette Vinnedge LM: Loss of DEK induces radioresistance of murine restricted hematopoietic progenitors. Exp Hematol 59: 40-50.e3, 2018.

18. Zhou QC, Deng XF, Yang J, Jiang H, Qiao MX, Liu HH, Qian Z, Hou LL and Hu HG: Oncogene DEK is highly expressed in lung cancerous tissues and positively regulates cell proliferation as well as invasion. Oncol Lett 15: 8573-8581, 2018.

19. Ou Y, Xia R, Kong F, Zhang X, Yu S, Jiang L, Zheng L and Lin L: Overexpression of DEK is an indicator of poor prognosis in patients with gastric adenocarcinoma. Oncol Lett 11: 1823-1828, 2016

20. Matrka MC, Watanabe M, Muraleedharan R, Lambert PF, Lane AN, Romick-Rosendale LE and Wells SI: Overexpression of the human DEK oncogene reprograms cellular metabolism and promotes glycolysis. PLoS One 12: e0177952, 2017.

21. Qiao MX, Li C, Zhang AQ, Hou LL, Yang J and Hu HG: Regulation of DEK expression by AP- $\alpha \alpha$ and methylation level of DEK promoter in hepatocellular carcinoma. Oncol Rep 36: 2382-2390, 2016

22. Xu Y, Liang Z, Li C, Yang Z and Chen L: LCMR1 interacts with DEK to suppress apoptosis in lung cancer cells. Mol Med Rep 16: 4159-4164, 2017.

23. Wang J, Sun L, Yang M, Luo W, Gao Y, Liu Z, Qiu X and Wang E: DEK depletion negatively regulates Rho/ROCK/MLC pathway in non-small cell lung cancer. J Histochem Cytochem 61: 510-521, 2013.

24. Liu K, Feng T, Liu J, Zhong M and Zhang S: Silencing of the DEK gene induces apoptosis and senescence in CaSki cervical carcinoma cells via the up-regulation of NF- $\kappa \mathrm{B}$ p65. Biosci Rep 32: 323-332, 2012.

25. Cserni G, Chmielik E, Cserni B and Tot T: The new TNM-based staging of breast cancer. Virchows Arch 472: 697-703, 2018.

26. Wang Y, Lei L, Zheng YW, Zhang L, Li ZH, Shen HY, Jiang GY, Zhang XP, Wang EH and Xu HT: Odd-skipped related 1 inhibits lung cancer proliferation and invasion by reducing Wnt signaling through the suppression of SOX9 and $\beta$-catenin. Cancer Sci 109: 1799-1810, 2018 .

27. Chandrashekar DS, Bashel B, Balasubramanya SAH, Creighton CJ, Ponce-Rodriguez I, Chakravarthi BVSK and Varambally S: UALCAN: A portal for facilitating tumor subgroup gene expression and survival analyses. Neoplasia 19: 649-658, 2017. 
28. Cerami E, Gao J, Dogrusoz U, Gross BE, Sumer SO, Aksoy BA Jacobsen A, Byrne CJ, Heuer ML, Larsson E, et al: The cBio cancer genomics portal: An open platform for exploring multidimensional cancer genomics data. Cancer Discov 2: 401-404, 2012.

29. Gao J, Aksoy BA, Dogrusoz U, Dresdner G, Gross B, Sumer SO, Sun Y, Jacobsen A, Sinha R, Larsson E, et al: Integrative analysis of complex cancer genomics and clinical profiles using the cBioPortal. Sci Signal 6: pl1, 2013.

30. Györffy B, Lanczky A, Eklund AC, Denkert C, Budczies J, Li Q and Szallasi Z: An online survival analysis tool to rapidly assess the effect of 22,277 genes on breast cancer prognosis using microarray data of 1,809 patients. Breast Cancer Res Treat 123: 725-731, 2010.

31. Bradford MM: A rapid and sensitive method for the quantitation of microgram quantities of protein utilizing the principle of protein-dye binding. Anal Biochem 72: 248-254, 1976.

32. Juríková M, Danihel L', Polák Š and Varga I: Ki67, PCNA, and MCM proteins: Markers of proliferation in the diagnosis of breast cancer. Acta Histochem 118: 544-552, 2016.

33. Yang Y, Gao M, Lin Z, Chen L, Jin Y, Zhu G, Wang Y and Jin T: DEK promoted EMT and angiogenesis through regulating $\mathrm{PI} 3 \mathrm{~K} / \mathrm{AKT} / \mathrm{mTOR}$ pathway in triple-negative breast cancer. Oncotarget 8: 98708-98722, 2017.

34. Liu S, Wang X, Sun F, Kong J, Li Z and Lin Z: DEK overexpression is correlated with the clinical features of breast cancer. Pathol Int 62: 176-181, 2012.

35. Ying $\mathrm{G}$ and $\mathrm{Wu} \mathrm{Y}$ : DEK: A novel early screening and prognostic marker for breast cancer. Mol Med Rep 12: 7491-7495, 2015.

36. Privette Vinnedge LM, McClaine R, Wagh PK, Wikenheiser-Brokamp KA, Waltz SE and Wells SI: The human DEK oncogene stimulates $\beta$-catenin signaling, invasion and mammosphere formation in breast cancer. Oncogene 30: 2741-2752, 2011

37. Zhang Y, Liu J, Wang S, Luo X, Li Y, Lv Z, Zhu J, Lin J, Ding L and Ye Q: The DEK oncogene activates VEGF expression and promotes tumor angiogenesis and growth in HIF-1 $\alpha$-dependent and -independent manners. Oncotarget 7: 23740-23756, 2016.
38. Feng T, Liu Y, LiC, LiZ and Cai H: DEK proto-oncogene is highly expressed in astrocytic tumors and regulates glioblastoma cell proliferation and apoptosis. Tumour Biol 39: 1010428317716248, 2017.

39. Xu X, Zou L, Yao Q, Zhang Y, Gan L and Tang L: Silencing DEK downregulates cervical cancer tumorigenesis and metastasis via the DEK/p-Ser9-GSK-3 $\beta /$ p-Tyr216-GSK-3 $\beta / \beta$-catenin axis. Oncol Rep 38: 1035-1042, 2017.

40. Sitwala KV, Adams K and Markovitz DM: YY1 and NF-Y binding sites regulate the transcriptional activity of the dek and dek-can promoter. Oncogene 21: 8862-8870, 2002.

41. Wise-Draper TM, Allen HV, Thobe MN, Jones EE, Habash KB, Münger K and Wells SI: The human DEK proto-oncogene is a senescence inhibitor and an upregulated target of high-risk human papillomavirus E7. J Virol 79: 14309-14317, 2005.

42. Carro MS, Spiga FM, Quarto M, Di Ninni V, Volorio S, Alcalay M and Müller H: DEK Expression is controlled by E2F and deregulated in diverse tumor types. Cell Cycle 5: 1202-1207, 2006.

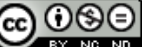

This work is licensed under a Creative Commons Attribution-NonCommercial-NoDerivatives 4.0 International (CC BY-NC-ND 4.0) License. 